\title{
Synthesis, Crystal Structure and Quantum Chemistry of a Novel Schiff Base $N$-(2,4-Dinitro-phenyl)- $N$ '-(1-phenyl-ethylidene)-hydrazine
}

\author{
Ning-Ning Ji, Zhi-Qiang Shi, ${ }^{\dagger, *}$ Ren-Gao Zhao, ${ }^{\dagger}$ Ze-Bao Zheng, and Zhi-Feng $\mathbf{L i}^{\ddagger}$ \\ Department of Chemistry and Environment Science, Taishan University, Taian, Shandong, 271021, P. R. China \\ 'Department of Materials science and Chemical Engineering, Taishan University, Taian, Shandong, 271021, P. R. China \\ "E-mail: kobeecho@163.com \\ ${ }^{\ddagger}$ College of Life Science and Chemistry, Tianshui Normal University, Tianshui, Gansu, 741001, P. R. China \\ Received November 4, 2009, Accepted February 3, 2010
}

\begin{abstract}
A novel Schiff base $N$-(2,4-dinitro-phenyl)- $N^{\prime}$-(1-phenyl-ethylidene)-hydrazine has been synthesized and structurally characterized by X-ray single crystal diffraction, elemental analysis, IR spectra and UV-vis spectrum. The crystal belongs to monoclinic with space group $P 21 / n$. The molecules are connected via intermolecular $\mathrm{O}-\mathrm{H} \cdots \mathrm{O}$ hydrogen bonds into 1D infinite chains. The crystal structure is consolidated by the intramolecular $\mathrm{N}-\mathrm{H} \cdots \mathrm{O}$ hydrogen bonds. weak intermolecular $\mathrm{C}-\mathrm{H} \cdots \mathrm{O}$ hydrogen bonds link the molecules into intriguing 3D framework. Furthermore, Density functional theory (DFT) calculations of the structure, stabilities, orbital energies, composition characteristics of some frontier molecular orbitals and Mulliken charge distributions of the title compound were performed by means of Gaussian $03 \mathrm{~W}$ package and taking B3LYP/6-31G(d) basis set. The time-dependent DFT calculations have been employed to calculate the electronic spectrum of the title compound, and the UV-vis spectra has been discussed on this basis. The results show that DFT method at B3LYP/6-31G(d) level can well reproduce the structure of the title compound.
\end{abstract}

Key Words: $N$-(2,4-Dinitro-phenyl)- $N$ '-(1-phenyl-ethylidene)-hydrazine, Crystal structure, Quantum chemistry calculation

\section{Introduction}

The chemical properties of aroyl hydrazones have been intensively investigated in several research fields mainly due to their facile syntheses, tuneable electronic and steric properties and good chelating capability. ${ }^{1}$ Especial the 2,4-dinitrophenylhydrazones exhibit good nonlinear optical (NLO) ${ }^{2-4}$ and crystalline properties. ${ }^{5-9}$ They are found to have versatile coordinating abilities towards different metal ions. In addition, some 2,4-dinitrophenylhydrazone derivatives have been shown to be potentially DNA-damaging and mutagenic agents. ${ }^{10}$ As a result of their significant molecular nonlinearities and remarkable ability to crystallize in non-centrosymmetric crystal systems, ${ }^{11,12}$ many X-ray structural studies of 2,4-dinitrophenylhydrazone have been reported. In order to obtain further information about 2,4dinitrophenylhydrazone, the title compound was prepared and its synthesis, crystal structure, spectroscopic data, and electronic structure of the title compound reported. Furthermore, quantum chemistry calculation was performed to disclose the stability, molecular orbital energy and frontier orbital constitution. The electronic structure of the title compound has been determined with the density functional theory (DFT) method, and timedependent DFT (TDDFT) calculations have been employed for discussion of the spectroscopic properties in more detail.

\section{Experimental Sections}

General. All chemicals were obtained from commercial sources and used without further purification. IR spectra were recorded on a Nicolet 6700 spectrometer with $\mathrm{KBr}$ pellets in the $4000 \sim 400 \mathrm{~cm}^{-1}$ region. Crystal structure determination was car- ried out on a Bruker Smart APEX II CCD diffractometer. C, H, and $\mathrm{N}$ elemental analyses were performed on a PE-2400(II) apparatus. UV spectrum was recorded on a Helis Alpha, Thermo spectrometer (specpure acetonitrile as solvent) in the 200 600 $\mathrm{nm}$ range.

Synthesis of the title compound. The title compound was prepared by reflux of (2,4-dinitro-phenyl)-hydrazine $(1.0 \mathrm{mmol})$ and 4-acetylphenoy $(1.0 \mathrm{mmol})$ in the presence of acetic acid in $50 \mathrm{~mL}$ ethanol. After refluxing $3 \mathrm{~h}$, the solution was stood at room temperature for 6 days, and a quantity of block red crystals were produced with $87.5 \%$ yield. mp $260-262{ }^{\circ} \mathrm{C}$. Anal. Calcd. (\%) for $\mathrm{C}_{14} \mathrm{H}_{12} \mathrm{~N}_{4} \mathrm{O}_{5}$ : C, 53.17; H, 3.82; N, 17.72. Found (\%): C, 53.12; H, 3.76; N, 17.81. Main IR peaks (KBr, $\left.v / \mathrm{cm}^{-1}\right) 3390$ $\left(v_{(\mathrm{O}-\mathrm{H})}\right), 3298\left(v_{(\mathrm{N}-\mathrm{H})}\right), 1619\left(v_{(\mathrm{C}=\mathrm{N})}\right), 1588\left(v_{\mathrm{as}\left(\mathrm{NO}_{2}\right)}\right), 1326\left(v_{\mathrm{s}\left(\mathrm{NO}_{2}\right)}\right)$. UV-vis (acetonitrile, $\lambda_{\max } / \mathrm{nm}$ ) 204, 266, and 385.8.

Crystal structure determination and refinement. A red blocklike single crystal of the title compound with dimensions of $0.15 \mathrm{~mm} \times 0.12 \mathrm{~mm} \times 0.10 \mathrm{~mm}$ was used for X-ray diffraction analysis. Data were collected at $295 \mathrm{~K}$ on a Bruker Smart APEX II CCD diffractometer equipped with a graphite-monochromatic Mo K $\alpha$ radiation $(\lambda=0.71073 \AA)$ using an $\omega$ scan mode. The structure was solved by direct methods with SHELX-97 program $^{13}$ and refined by full-matrix least-squares techniques on $F^{2}$ with SHELXL-97. ${ }^{14}$ All non-hydrogen atoms were refined anisotropically. Hydrogens attached to carbon atoms were included at their geometrical positions and refined in the riding mode. Amine and hydroxyl protons were located in a difference Fourier map and refined isotropically and no restrictions put on the D-H distance. The crystallographic data for the compound are listed in Table 1, selected bond lengths and angles are listed in Table 2, the details of the hydrogen bonds for the compound 
are listed in Table 3.

Quantum chemical calculation. All the calculations have been performed with the Gaussian 03 software package ${ }^{15}$ on a Pentium IV computer using the default convergence criteria. The full geometry optimizations were performed starting from the experimental structure without constraints on symmetry at density functional theory (DFT) level with basis set 6-31G(d) and stationary points (including excited states) were characterized by frequency calculations. For DFT calculations, the hybrid B3LYP density functional (Becke's three parameter nonlocal exchange functional along with the Lee-Yang-Parr correlation functional) ${ }^{16}$ was used. After optimizations, Mulliken charge and properties of frontier molecular orbitals of the title compound were analyzed using the results calculated at B3LYP/6$31 G(d)$ level. The vertical excitation energies and oscillator strengths in low-lying singlet exited states were calculated at the TDDFT method at B3LYP/6-31G(d) level based on the optimized geometry.

\section{Results and Discussion}

Structural description. The molecular structure of the title compound is revealed in Figure 1, 1D infinite chain structure in Figure 2 and its 3D framework in Figure 3.

As shown in Figure 1 and Table 1, the bond lengths and angles in the title compound have normal values. The molecule, except the C8-methyl group, displays a nearly co-planar structure. The dihedral angle between the two aromatic rings is $5.04(2)^{\circ}$. The N1-C7 bond distance of 1.287(3) $\AA$ is significantly shorter than N1-N2 and N2-C9 bond distances, and indicates the typical $\mathrm{C}=\mathrm{N}$ double bond. The N2-C9 bond distance of 1.344(3) $\AA$ indicates partial double-bond character. It should be noted that, within the phenyl ring attached to N2, both the $\mathrm{C} 9-\mathrm{C} 10$ bond [1.414(4) $\AA]$ and the C9-C14 bond [1.417(4) $\AA$ ] are significantly longer than the average distance of 1.376(3) $\AA$ for the other four C-C bonds (range from 1.361(4), 1.397(4), 1.364(4) to 1.381(4) $\AA)$. This is presumably due to the fact that the non-bonding orbital of nitrogen can overlap with the orbitals of the arene, thus contributing to the iminocyclohexadiene resonance structure. ${ }^{17}$ The C7=N1-N2 angle is $116.9(2)^{\circ}$, which is significantly smaller than the ideal value of $120^{\circ}$ expected for $s p^{2}$-hybridized $\mathrm{N}$ atoms. This is probably a consequence of repulsion between the nitrogen lone pairs and the adjacent N-N bond.

As anticipated, the $\mathrm{N}-\mathrm{H}$ and $\mathrm{O}-\mathrm{H}$ of the title compound are involved in classical hydrogen bonds. The $\mathrm{O}-\mathrm{H} \cdots \mathrm{O}(\mathrm{O}(1)-\mathrm{H}(1) \cdots$ $\mathrm{O}(4)^{\mathrm{a}} 2.07 \AA, 177.1^{\circ}$, symmetry code: $\left.x-1, y-1, z\right)$ intermolecular hydrogen bond shaped by hydroxy group and one of the nitro groups link the molecules into a 1D infinite chain as shown in Figure 2 . The $\mathrm{H} \cdots \mathrm{O}$ diatance of $2.07 \AA$ which is significantly shorter than the van der Waals separation between the $\mathrm{O}$ atom and $\mathrm{H}$ atom $(2.72 \AA)^{18}$ and the $\mathrm{O}(1)-\mathrm{H}(1) \cdots \mathrm{O}(4)^{\mathrm{a}}$ angle of $177.1^{\mathrm{o}}$ which is nearly equal to $180^{\circ}$ indicate the existence of the strong $\mathrm{O}-\mathrm{H} \cdots \mathrm{O}$ interaction. The $\mathrm{N}-\mathrm{H} \cdots \mathrm{O}\left(\mathrm{N}(2)-\mathrm{H}(2) \cdots \mathrm{O}(2)^{\mathrm{b}} 1.99 \AA\right.$, $127.8^{\circ}$, symmetry code: $\left.x, y, z\right)$ intramolecular hydrogen bond formed by another nitro group and one of the hydrazone $\mathrm{N}$ atoms help to consolidate the crystal structure. The $\mathrm{H} \cdots \mathrm{O}$ diatance of 1.99 A illustrates the existence of the strong $\mathrm{N}-\mathrm{H} \cdots \mathrm{O}$ interaction. Furthermore, the $\mathrm{O}(2)$ atom also has weak interaction with $\mathrm{C}(5)$

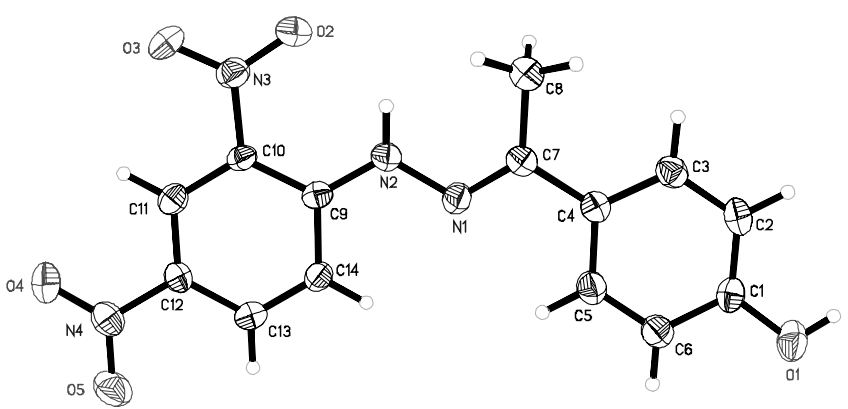

Figure 1. Molecular structure of the title compound.

Table 1. Crystal data and structure refinement parameters for the title compound

$\begin{array}{lc}\text { Chemical formula } & \mathrm{C}_{14} \mathrm{H}_{12} \mathrm{~N}_{4} \mathrm{O}_{5} \\ \text { Formula weight } & 316.28 \\ \text { Crystal system } & \text { Monoclinic } \\ \text { Space group } & P 21 / n \\ a / \AA & 12.778(2) \\ b / \AA & 8.1483(14) \\ c / \AA & 14.394(3) \\ \alpha /^{\circ} & 90.00 \\ \beta /^{\circ} & 109.893(4) \\ \gamma / /^{\circ} & 90 \\ V / \AA^{3} & 1409.3(4) \\ Z & 4 \\ D_{\text {cacl }} / \mathrm{g} \cdot{ }^{\circ} \mathrm{cm}^{-3} & 1.491 \\ \text { Absorption coefficient } / \mathrm{mm}^{-1} & 0.116 \\ \mathrm{~F}(000) & 656 \\ \text { Reflections collected } & 7198 \\ \text { Independent reflections } & 2490 \\ \text { Theta range(deg) } & 1.84 \text { to } 25.05 \\ R_{\text {int }} & 0.0144 \\ \text { Goodness-of-fit on } F^{2} & 1.030 \\ \text { Large diff. Peak and hole } / \mathrm{e} . \AA^{-3} & 0.184,-0.190 \\ R_{1}, w R_{2}[I>2 \sigma(I)] & 0.0485,0.0906 \\ R_{1}, w R_{2} \text { (all data) } & 0.1256,0.1204 \\ & \end{array}$

via a nonclassical intermolecular hydrogen bond, $\mathrm{C}(5)-\mathrm{H}(5) \cdots$ $\mathrm{O}(2)^{\mathrm{c}}$ diatance of 3.340 (4) $\AA$ and angle of $137.6^{\circ}$. The weak intermolecular hydrogen bond interactions further extend the $1 \mathrm{D}$ arrangement to generate an intriguing $3 \mathrm{D}$ framework as shown in Figure 3.

DFT calculations. The calculated structural parameters are listed in Table 2. Comparisons between the theoretical values with the experimental ones indicate that most of the optimized bond lengths are slightly larger than the experimental values, as the experimental data belong to solid phase, whereas the calculated data correspond to the isolated molecule in gas phase. The geometry of the solid-state structure is subject to intermolecular forces, such as van der Waals interactions, crystal packing forces and hydrogen-bond forces. ${ }^{19}$ The largest difference between experimental and calculated N2-H2 length is $0.1582 \AA$, whereas the biggest deviation occurs in the C9-N2-H2 


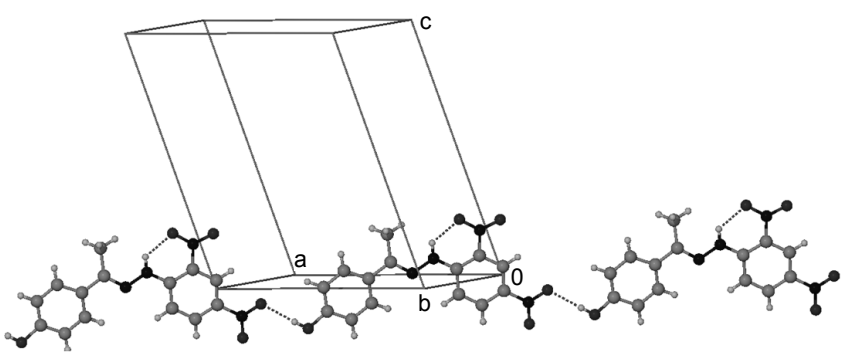

Figure 2. 1D infinite chain structure of the title compound. Hydrogen bonds are shown as dashed lines.

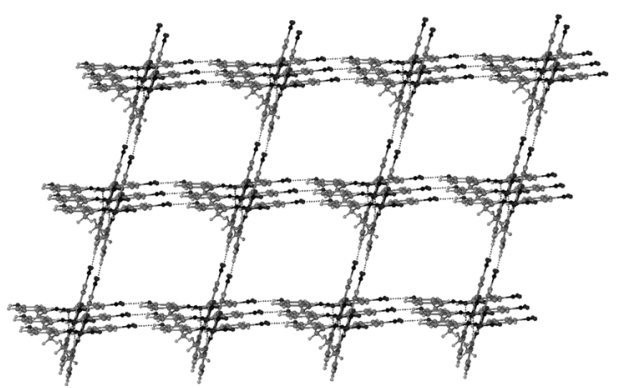

Figure 3. 3D framework of the title compound. Hydrogen bonds are shown as dashed lines.

Table 2. Selected bond lengths $(\AA)$ and angles $\left({ }^{\circ}\right)$ by X-ray and theoretical calculations

\begin{tabular}{lcclcc}
\hline Bond Lengths & Exp. & Cal. & Bond Angles & Exp. & Cal. \\
\hline $\mathrm{N}(1)-\mathrm{N}(2)$ & $1.377(3)$ & 1.3624 & $\mathrm{C}(7)-\mathrm{N}(1)-\mathrm{N}(2)$ & $117.0(2)$ & 117.3064 \\
$\mathrm{~N}(1)-\mathrm{C}(7)$ & $1.287(3)$ & 1.2978 & $\mathrm{C}(9)-\mathrm{N}(2)-\mathrm{N}(1)$ & $119.3(2)$ & 120.9618 \\
$\mathrm{~N}(2)-\mathrm{C}(9)$ & $1.344(3)$ & 1.3592 & $\mathrm{C}(9)-\mathrm{N}(2)-\mathrm{H}(2)$ & 120.4 & 115.9454 \\
$\mathrm{~N}(3)-\mathrm{O}(2)$ & $1.239(3)$ & 1.2489 & $\mathrm{~N}(1)-\mathrm{N}(2)-\mathrm{H}(2)$ & 120.4 & 123.0828 \\
$\mathrm{~N}(3)-\mathrm{O}(3)$ & $1.224(3)$ & 1.228 & $\mathrm{~N}(1)-\mathrm{C}(7)-\mathrm{C}(4)$ & $115.1(3)$ & 116.52783 \\
$\mathrm{~N}(4)-\mathrm{O}(4)$ & $1.228(3)$ & 1.2319 & $\mathrm{~N}(1)-\mathrm{C}(7)-\mathrm{C}(8)$ & $124.6(3)$ & 122.64988 \\
$\mathrm{~N}(4)-\mathrm{O}(5)$ & $1.227(3)$ & 1.2333 & $\mathrm{C}(4)-\mathrm{C}(7)-\mathrm{C}(8)$ & $120.3(3)$ & 120.82015 \\
$\mathrm{~N}(3)-\mathrm{C}(10)$ & $1.443(3)$ & 1.4521 & $\mathrm{~N}(2)-\mathrm{C}(9)-\mathrm{C}(10)$ & $123.5(3)$ & 122.33330 \\
$\mathrm{~N}(4)-\mathrm{C}(12)$ & $1.448(4)$ & 1.4594 & $\mathrm{~N}(2)-\mathrm{C}(9)-\mathrm{C}(14)$ & $119.8(3)$ & 120.52227 \\
$\mathrm{C}(4)-\mathrm{C}(7)$ & $1.471(4)$ & 1.4775 & $\mathrm{C}(11)-\mathrm{C}(12)-\mathrm{N}(4)$ & $119.0(3)$ & 119.32086 \\
$\mathrm{C}(7)-\mathrm{C}(8)$ & $1.502(4)$ & 1.5137 & $\mathrm{C}(13)-\mathrm{C}(12)-\mathrm{N}(4)$ & $119.9(3)$ & 119.68007 \\
$\mathrm{C}(1)-\mathrm{O}(1)$ & $1.369(3)$ & 1.3623 & $\mathrm{O}(4)-\mathrm{N}(4)-\mathrm{C}(12)$ & $118.6(3)$ & 117.93309 \\
$\mathrm{O}(1)-\mathrm{H}(1)$ & 0.8200 & 0.9702 & $\mathrm{O}(5)-\mathrm{N}(4)-\mathrm{C}(12)$ & $118.6(3)$ & 117.38660 \\
$\mathrm{~N}(2)-\mathrm{H}(2)$ & 0.8600 & 1.0182 & $\mathrm{O}(4)-\mathrm{N}(4)-\mathrm{O}(5)$ & $122.8(3)$ & 124.68030 \\
$\mathrm{C}(9)-\mathrm{C}(10)$ & $1.414(4)$ & 1.4316 & $\mathrm{C}(9)-\mathrm{C}(10)-\mathrm{N}(3)$ & $121.9(3)$ & 122.60626 \\
$\mathrm{C}(10)-\mathrm{C}(11)$ & $1.381(4)$ & 1.3963 & $\mathrm{C}(11)-\mathrm{C}(10)-\mathrm{N}(3)$ & $115.9(3)$ & 116.34878 \\
$\mathrm{C}(11)-\mathrm{C}(12)$ & $1.364(4)$ & 1.3809 & $\mathrm{O}(2)-\mathrm{N}(3)-\mathrm{C}(10)$ & $118.9(3)$ & 118.68404 \\
$\mathrm{C}(12)-\mathrm{C}(13)$ & $1.397(4)$ & 1.4061 & $\mathrm{O}(3)-\mathrm{N}(3)-\mathrm{C}(10)$ & $119.4(3)$ & 118.73183 \\
$\mathrm{C}(13)-\mathrm{C}(14)$ & $1.361(4)$ & 1.3752 & $\mathrm{O}(2)-\mathrm{N}(3)-\mathrm{O}(3)$ & $121.7(3)$ & 122.58412 \\
$\mathrm{C}(9)-\mathrm{C}(14)$ & $1.417(4)$ & 1.4217 & & & \\
\hline
\end{tabular}

angle by $c a .4 .4546^{\circ}$. The reasons for above discrepances maybe that, in the solid states, there exist hydrogen-bond interactions corresponding with $\mathrm{N} 1-\mathrm{H} 2$ bond, while in theoretical calculations, the interactions are neglected, which, to some extent, may lead to the bond angle of C9-N2-H2 smaller in solid than that in calculations. Despite of some differences, the calculated geometrical parameters represent a good approximation. So the DFT methods used here can reproduce the molecular geometry on the whole and they are the bases for our following discussion.

Energy and constitution of FMOs. The FMOs are important in determining such properties as molecular reactivity and the ability of a molecular to absorb light. These FBOs are important for optical and electric properties. ${ }^{20}$ According to the quantum chemical calculations, the single point energy and frontier molecular orbitals were calculated. 35 atoms, 369 basis functions, 692 primitive gaussians, including 82 occupied orbitals, are involved in the calculation.

On the basis of molecular orbital theory, the HOMO-LUMO
Table 3. Hydrogen bonds geometries $\left(\AA,^{\circ}\right)$ for the title compound

\begin{tabular}{ccccc}
\hline $\mathrm{D}-\mathrm{H} \cdots \mathrm{A}$ & $\mathrm{d}(\mathrm{D}-\mathrm{H})$ & $\mathrm{d}(\mathrm{H} \cdots \mathrm{A})$ & $\mathrm{d}(\mathrm{D} \cdots \mathrm{A})$ & $\angle \mathrm{DHA}$ \\
\hline $\mathrm{O}(1)-\mathrm{H}(1) \cdots \mathrm{O}(4)^{a}$ & 0.82 & 2.07 & $2.893(3)$ & 177.1 \\
$\mathrm{~N}(2)-\mathrm{H}(2) \cdots \mathrm{O}(2)^{b}$ & 0.86 & 1.99 & $2.603(3)$ & 127.8 \\
$\mathrm{C}(5)-\mathrm{H}(5) \cdots \mathrm{O}(2)^{c}$ & 0.93 & 2.59 & $3.340(4)$ & 137.6
\end{tabular}

Symmetry codes: ${ }^{a} x-1, y-1, z^{b} x, y, z^{c} x-1 / 2,-y+1 / 2, z-1 / 2$

and the vicinal molecular orbital affect the property of coordination mostly. ${ }^{21}$ The molecules will be stable when the energies of occupied front molecular orbitals are all negative values. ${ }^{22}$ The energy levels of the HOMO-7, HOMO-5, HOMO-1, HOMO, LUMO, LUMO+1, LUMO+2 and LUMO+4 orbitals computed at the B3LYP/6-31G(d) level for the title compound are shown in Figure 6. The energy of HOMO and LUMO and the energy gap are -0.21 a.u. $(-5.91 \mathrm{eV}),-0.10$ a.u. $(-2.78 \mathrm{eV})$ and 0.11 a.u. $(3.13 \mathrm{eV})$. The total energy $(-1135.62 \mathrm{a} . \mathrm{u})$ of the title compound 
Table 4. Some calculated frontier molecular orbital composition (\%) of the title compound

\begin{tabular}{ccrrrrrrrr}
\hline MO & $\varepsilon /$ Hartree & $\mathrm{N}(\mathrm{I})$ & $\mathrm{N}(\mathrm{II})$ & $\mathrm{O}(\mathrm{I})$ & $\mathrm{O}(\mathrm{II})$ & $\mathrm{C}(\mathrm{I})$ & $\mathrm{C}(\mathrm{II})$ & $\mathrm{C}(\mathrm{III})$ & $\mathrm{H}$ \\
\hline 78 & -0.29 & 38.90 & 0.90 & 0.03 & 34.68 & 6.60 & 5.91 & 10.96 & 2.03 \\
79 & -0.29 & 0.90 & 1.50 & 0.00 & 83.44 & 0.11 & 13.26 & 0.20 & 0.58 \\
80 & -0.27 & 1.19 & 0.01 & 0.00 & 0.24 & 97.14 & 0.57 & 0.61 & 0.23 \\
81 & -0.26 & 13.86 & 0.17 & 15.29 & 4.26 & 32.50 & 26.74 & 5.71 & 1.48 \\
$82 \mathrm{HOMO}$ & -0.21 & 30.59 & 0.78 & 8.74 & 4.94 & 30.56 & 16.63 & 6.71 & 1.07 \\
$83 \mathrm{LUMO}$ & -0.10 & 2.98 & 27.63 & 0.19 & 37.57 & 1.55 & 27.82 & 1.98 & 0.28 \\
84 & -0.09 & 3.32 & 23.39 & 0.38 & 34.21 & 3.40 & 29.79 & 4.02 & 1.46 \\
85 & -0.05 & 24.01 & 6.78 & 2.45 & 6.54 & 29.08 & 13.53 & 12.88 & 4.73 \\
86 & -0.02 & 1.20 & 0.20 & 0.02 & 0.13 & 90.82 & 1.70 & 3.71 & 2.24 \\
87 & -0.01 & 3.37 & 13.76 & 0.43 & 8.72 & 7.88 & 65.21 & 0.27 & 0.37 \\
\hline
\end{tabular}

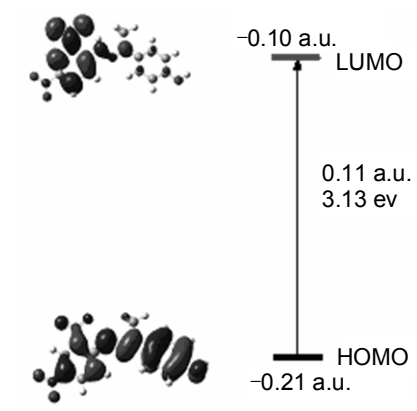

Figure 4. Schematic diagram of the frontier MO for the title compound.

is lower and the energies of HOMO, LUMO and their neighboring orbital are all negative, which indicate that the title compound is stable. The HOMO and its vicinal orbital play the role of electron donors, and the LUMO and its vicinal orbital play the role of electron accepters. ${ }^{23}$ From the viewpoint of charge transfer, larger $|\varepsilon \mathrm{HOMO}|$ means that ionization from $\mathrm{HOMO}$ is more difficult, that is to say, the title compound is hard to lose electron.

In order to disclose the electronic structure and bonding character of the title compound, systematical analysis on the molecular orbitals has been carried out. Here, the orbital component was assigned according to the percentage of orbital coefficient quadratic sum and normalization. For the convenience of discussion, the atoms of the title compound are divided into seven groups: (a) azomethine $\mathrm{N}$ atoms (N(I)), (b) nitro $\mathrm{N}$ atoms (N(II)), (c) hydroxyl $\mathrm{O}$ atom $(\mathrm{O}(\mathrm{I}))(\mathrm{d})$ nitro $\mathrm{O}$ atoms $(\mathrm{O}(\mathrm{II}))$, (e) $\mathrm{C}$ atoms on the 4-acetylphenoy benzene ring (C(I)), (f) $\mathrm{C}$ atoms on the (2,4-dinitro-phenyl)-hydrazine benzene ring (C(II)), (g) non

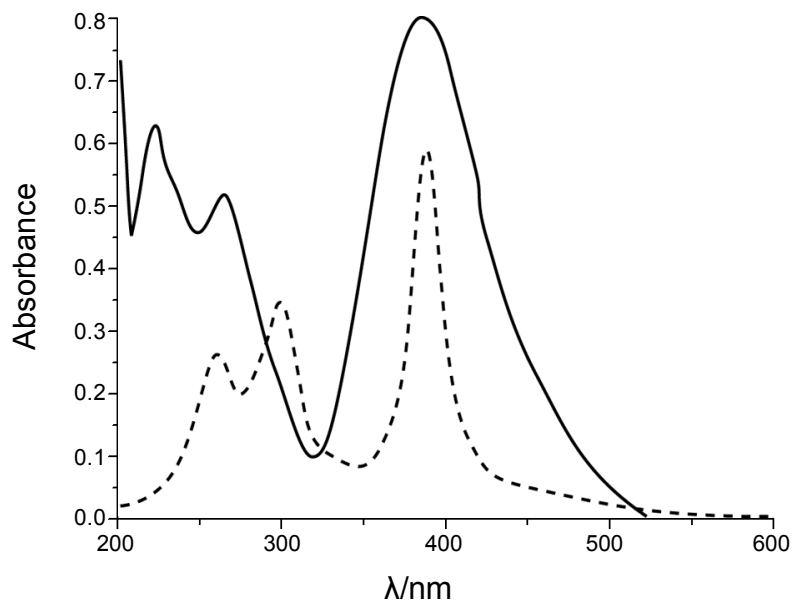

Figure 5. The experimental (-) and calculated (-----) electronic absorption spectra of the title compound.

benzene ring $\mathrm{C}$ atoms (CIII), (h) hydrogen atoms $\mathrm{H}$. Five frontier occupied and unoccupied orbitals were taken into account in this paper, and the calculation results are shown in Table 4 and Figure 4.

As will be seen in Figure 4, the HOMO of the title compound is principally localized among two benzene rings and azomethine $\mathrm{N}$ atoms, whereas the LUMO is localized approximately on the 4-acetylphenoy benzene ring and nitro $\mathrm{N}$ atoms. According to our analysis, in the HOMO, the components of $\mathrm{N}(\mathrm{I}), \mathrm{C}(\mathrm{I})$ and C(II) are $30.59,30.56$ and $16.63 \%$, respectively. The other atoms contribute to the molecular orbital are relative small. In the LUMO, the contribution of most atoms to LUMO changes greatly. The contribution of N(II) reaches $27.63 \%$. The contribu-

Table 5. The Mulliken charges (e) for the title compound

\begin{tabular}{cccccccccc}
\hline Atom & Charge $(e)$ & Atom & Charge $(e)$ & Atom & Charge $(e)$ & Atom & Charge $(e)$ & Atom & Charge $(e)$ \\
\hline $\mathrm{N}(1)$ & -0.303 & $\mathrm{O}(4)$ & -0.399 & $\mathrm{C}(6)$ & -0.161 & $\mathrm{C}(13)$ & -0.145 & $\mathrm{H}(6)$ & 0.150 \\
$\mathrm{~N}(2)$ & -0.586 & $\mathrm{O}(5)$ & -0.401 & $\mathrm{C}(7)$ & 0.290 & $\mathrm{C}(14)$ & -0.180 & $\mathrm{H}(8 \mathrm{~A})$ & 0.188 \\
$\mathrm{~N}(3)$ & 0.375 & $\mathrm{C}(1)$ & 0.360 & $\mathrm{C}(8)$ & -0.565 & $\mathrm{H}(1)$ & 0.412 & $\mathrm{H}(8 \mathrm{~B})$ & 0.180 \\
$\mathrm{~N}(4)$ & 0.373 & $\mathrm{C}(2)$ & -0.198 & $\mathrm{C}(9)$ & 0.402 & $\mathrm{H}(2)$ & 0.396 & $\mathrm{H}(8 \mathrm{C})$ & 0.188 \\
$\mathrm{O}(1)$ & -0.633 & $\mathrm{C}(3)$ & -0.194 & $\mathrm{C}(10)$ & 0.245 & $\mathrm{H}(2 \mathrm{~A})$ & 0.127 & $\mathrm{H}(11)$ & 0.227 \\
$\mathrm{O}(2)$ & -0.451 & $\mathrm{C}(4)$ & 0.105 & $\mathrm{C}(11)$ & -0.2086 & $\mathrm{H}(3)$ & 0.138 & $\mathrm{H}(13)$ & 0.191 \\
$\mathrm{O}(3)$ & -0.386 & $\mathrm{C}(5)$ & -0.163 & $\mathrm{C}(12)$ & 0.280 & $\mathrm{H}(5)$ & 0.156 & $\mathrm{H}(14)$ & 0.186 \\
\hline
\end{tabular}


Table 6. The energy and molar absorption coefficients of experimental absorption bands and the electronic transitions calculated with the TDDFT method for the title compound

\begin{tabular}{ccccc}
\hline $\begin{array}{c}\text { The most important } \\
\text { orbital excitations }\end{array}$ & $\lambda(\mathrm{nm})$ & $E(\mathrm{eV})$ & $f$ & $\begin{array}{c}\text { Experimental } A \\
(\mathrm{~nm})(E(\mathrm{eV}))\end{array}$ \\
\hline $\mathrm{H} \rightarrow \mathrm{L}+1$ & 387.26 & 3.20 & 0.5706 & $385(3.48)$ \\
$\mathrm{H}-1 \rightarrow \mathrm{L}$ & 330.05 & 3.76 & 0.0203 & \\
$\mathrm{H}-4 \rightarrow \mathrm{L}$ & 328.08 & 3.78 & 0.0068 & \\
$\mathrm{H}-1 \rightarrow \mathrm{L}+1$ & 298.92 & 4.15 & 0.2703 & $264(4.59)$ \\
$\mathrm{H}-2 \rightarrow \mathrm{L}$ & 296.80 & 4.18 & 0.0016 & \\
$\mathrm{H}-8 \rightarrow \mathrm{L}$ & 290.26 & 4.27 & 0.0003 & \\
$\mathrm{H}-6 \rightarrow \mathrm{L}+1$ & 287.49 & 4.31 & 0.0001 & \\
$\mathrm{H} \rightarrow \mathrm{L}+2$ & 283.98 & 4.37 & 0.0856 & \\
$\mathrm{H}-2 \rightarrow \mathrm{L}+1$ & 274.17 & 4.52 & 0.0017 & \\
$\mathrm{H}-4 \rightarrow \mathrm{L}+1$ & 260.96 & 4.75 & 0.0040 & \\
$\mathrm{H}-5 \rightarrow \mathrm{L}$ & 259.96 & 4.77 & 0.1331 & $221.8(5.26)$ \\
$\mathrm{H} \rightarrow \mathrm{L}+3$ & 258.35 & 4.80 & 0.0325 & \\
$\mathrm{H}-5 \rightarrow \mathrm{L}+1$ & 254.68 & 4.87 & 0.0096 & \\
$\mathrm{H}-6 \rightarrow \mathrm{L}$ & 253.62 & 4.89 & 0.0004 & \\
$\mathrm{H}-7 \rightarrow \mathrm{L}$ & 248.23 & 4.99 & 0.0166 & \\
$\mathrm{H} \rightarrow \mathrm{L}+4$ & 245.87 & 5.04 & 0.0580 & \\
$\mathrm{H}-11 \rightarrow \mathrm{L}$ & 242.79 & 5.12 & 0.0001 & \\
\hline
\end{tabular}

$f$ : oscillator strength. $\mathrm{H}$ : highest occupied molecular orbital. L: lowest unoccupied molecular orbital.

tion of $\mathrm{O}(\mathrm{II})$ and $\mathrm{C}(\mathrm{II})$ increases to 37.57 and $27.82 \%$, respectively. Upon comparing the orbital component of $\mathrm{HOMO}$ and LUMO, it is easy to conclude that when electrons are excited from HOMO to LUMO, they will mainly transmit from the 4-acetylphenoy benzene ring and azomethine $\mathrm{N}$ atoms to the (2,4-dinitro-phenyl)-hydrazine benzene ring.

Mulliken charge distribution. Based on the optimized structure of the title compound, the Mulliken charge distribution of all atoms is calculated and the results are given in Table 5. The result shows that atomic electronegativity plays important roles for Mulliken charge distribution. Namely, between the two connecting atoms, the atom having bigger electronegativity will carry negative charges, while the atom having smaller electronegativity will carry positive charges. ${ }^{19}$ So, for the title compound, $\mathrm{N}$ (from nitro group), $\mathrm{H}$ and $\mathrm{C}$ (non-bonding with $\mathrm{H}$ atoms) are all positive. $\mathrm{N}$ (from amine group), $\mathrm{O}$ and $\mathrm{C}$ (bonding with $\mathrm{H}$ atoms) are all negative. On the other hand, $\mathrm{O}(1)$ and $\mathrm{N}(2)$, are more negative and could act as electron donor when coordinating with metals. The analysis of the Mulliken charge distributions is consistent with the crystal determination.

Electronic spectra. The nature of the transitions observed in the UV-vis spectra of the title compound has been studied by the time-dependent density functional (TDDFT) method. The calculated and experimental electronic spectrum are presented in Figure 5. As seen from the Figure 5, TDDFT calculations well reproduce the absorption spectrum of the title compound. Table 6 presents the most important electronic transitions calculated with the TDDFT method for the title compound. The assignment of the calculated orbital excitations to the experimental bands
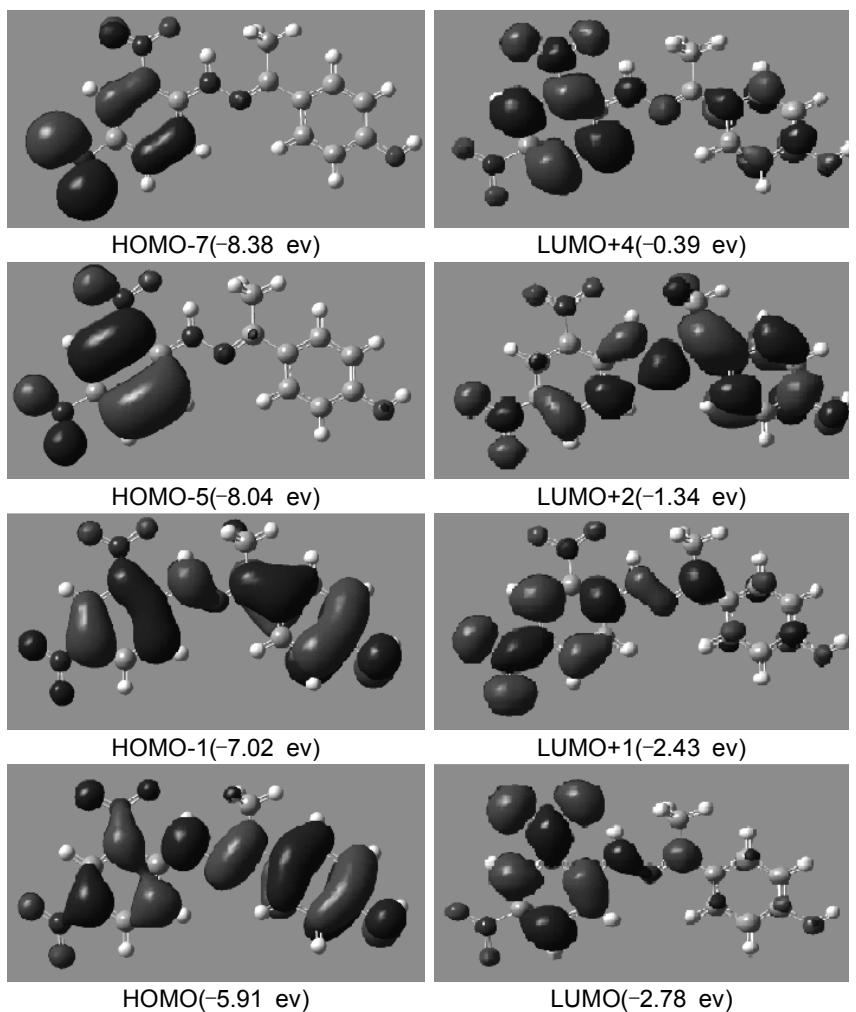

Figure 6. Contour plots and energy of the selected occupied and unoccupied orbitals active in the electronic transitions.

was based on an overview of the contour plots and relative energy of HOMO and LUMO molecular orbitals involved in the electronic transitions (Figure 6). The TDDFT calculations show that the longest wavelength experimental band at $385 \mathrm{~nm}$ originates in the $\mathrm{HOMO} \rightarrow \mathrm{LUMO}+1$ transitions. The experimental band at 264 and $221.8 \mathrm{~nm}$ originates predominately in the HOMO- $1 \rightarrow$ LUMO+1 and HOMO- $5 \rightarrow$ LUMO transitions, respectively. As can be seen from the Figure 6, The HOMO-1 is delocalized on the whole compound whereas the LUMO+1 is centered on the $\pi$-bonding orbitals of (2,4-dinitro-phenyl)hydrazine benzene ring and azomethine $\mathrm{N}$ atoms. Otherwise, the HOMO-5 is centered on the (2,4-dinitro-phenyl)-hydrazine benzene ring.

Supplementary Material. Crystallographic data for the structure reported here have been deposited with the Cambridge Crystallographic Data Centre (Deposition No. CCDC-714150). The data can be obtained free of charge via http://www.ccdc.cam. ac.uk/perl/catreq.cgi or from the CCDC, 12 Union Road, Cambridge CB2 1EZ, UK; fax: +44 1223 336033; e-mail: deposit@ ccdc.cam.ac.uk.

Acknowledgments. This work was supported by the Postgraduate Foundation of Taishan University (No.Y07-2-16).

\section{References}

1. Raj, B. N. B.; Kurup, M. R. P. Spectrochimica Acta Part A 2007 , 66, 898. 
2. Cariati, F.; Caruso, U.; Centore, R.; Marcolli, W.; Maria, A. D.; Panunzi, B.; Roviello, A.; Tuzi, A. Inorg. Chem. 2002, 41, 6597.

3. Lacroix, P. G. Eur. J. Inorg. Chem. 2001, 2, 339.

4. Caruso, U.; Centore, R.; Panunzi, B.; Roviello, A.; Tuzi, A. Eur. J. Inorg. Chem. 2005, 2747.

5. Bauhman, R. G.; Martin, K, L.; Singh, R. K.; Stoffer, J. O. Acta Cryst. C 2004, 60, 103.

6. Pelizzi, C.; Pelizzi, G. J. Chem. Soc., Dalton Trans. 1980, 1970.

7. Das, S.; Pal, S. J. Mol. Struct. 2005, 741, 183.

8. Dey, D. K.; Lycka, A.; Mitra, S.; Rosair, G. M. J. Organomet. Chem. 2004, 689, 88.

9. Carcelli, M.; Ianelli, S.; Pelagatti, P.; Pelizzi, G.; Rogolino, D.; Solinas, C.; Tegoni, M. Inorg. Chim. Acta 2005, 358, 903.

10. Okabe, N.; Nakamura, T.; Fukuda, H. Acta Cryst. C 1993, 49, 1678.

11. Zare, H. R.; Ardakani, M. M.; Nasirizadah, N.; Safari, J. Bull. Korean Chem. Soc. 2005, 26, 51.

12. El-Seify, F. A.; El-Dossoki, F. I. J. Korean Chem. Soc. 2006, 50, 99.

13. Sheldrick, G. M. SHELX 97, Program for the Solution of Crystal Structure, University of Göttingen, Germany 1997.

14. Sheldrick, G. M. SHELXS 97, Program for the Refinement of Crystal Structure, University of Göttingen, Germany 1997.

15. Frisch, M. J.; Trucks, G. W.; Schlegel, H. B.; Scuseria, G. E.; Robb, M. A.; Cheeseman, J. R.; Montgomery, J. A.; Vreven, T., Jr.; Kudin, K. N.; Burant, J. C.; Millam, J. M.; Iyengar, S. S.; Tomasi, J.; Barone, V.; Mennucci, B.; Cossi, M.; Scalmani, G.; Rega, N.; Petersson, G. A.; Nakatsuji, H.; Hada, M.; Ehara, M.; Toyota, K.;
Fukuda, R.; Hasegawa, J.; Ishida, M.; Nakajima, T.; Honda, Y.; Kitao, O.; Nakai, H.; Klene, M.; Li, X.; Knox, J. E.; Hratchian, H. P.; Cross, J. B.; Adamo, C.; Jaramillo, J.; Gomperts, R.; Stratmann, R. E.; Yazyev, O.; Austin, A. J.; Cammi, R.; Pomelli, C.; Ochterski, J. W.; Ayala, P. Y.; Morokuma, K.; Voth, G. A.; Salvador, P.; Dannenberg, J. J.; Zakrzewski, V. G.; Dapprich, S.; Daniels, A. D.; Strain, M. C.; Farkas, O.; Malick, D. K.; Rabuck, A. D.; Raghavachari, K.; Foresman, J. B.; Ortiz, J. V.; Cui, Q.; Baboul, A. G.; Clifford, S.; Cioslowski, J.; Stefanov, B. B.; Liu, G.; Liashenko, A.; Piskorz, P.; Komaromi, I.; Martin, R. L.; Fox, D. J.; Keith, T.; AlLaham, M. A.; Peng, C. Y.; Nanayakkara, A.; Challacombe, M.; Gill, P. M. W.; Johnson, B.; Chen, W.; Wong, M. W.; Gonzalez, C.; Pople, J. A. Gaussian, Inc.: Wallingford, CT, 2004.

16. (a) Becke, A. D. J. Chem. Phys. 1993, 98, 5648. (b) Lee, C.; Yang, W.; Parr, R. G. Phys. Rev. B 1988, 37, 785.

17. Shang, S.; Xu, D. J.; Wu, J. Y.; Chiang, M. Y. Acta Cryst. E 2002, 58,01333 .

18. Bondi A. J. Phys. Chem. 1964, 68, 443.

19. Zhao, P. S.; Shao, D. L.; Zhang, J.; Wei, Y.; Jian, F. F. Bull. Korean Chem. Soc. 2009, 30, 1668.

20. Fleming, I. Frontier Orbitals and Organic Chemical Reactions; John Wiley \& Sons: New York, 1976.

21. Guo, F.; Bi, C. F.; Fan, Y. H.; Wang, A. D.; Xu, J. K.; Zhang, X. J. Ocean Univ. Chin. 2008, 7, 168.

22. Xia, S. W.; Xu, X.; Sun, Y. L.; Fan, Y. H.; Bi, C. F.; Zhang, D. M.; Yang, L. R. Chin. J. Struct. Chem. 2006, 25, 200.

23. Dong, M.; Zhu, H. L.; Zhang, X.; Xu, H. Z. Chin.J. Tianjin Norm. Univ. (Natural Science Edition) 2005, 25, 14. 